Article

\title{
Time-Series Displacement of Landslide In Danba County (China) Monitoried By the Small Baseline Subset (SBAS) technique
}

\author{
Bo Hu ${ }^{1, *}$, Yang $\mathrm{Wu}^{1}$ \\ ${ }^{1}$ Guangdong university of technology, Guangzhou, 510006, China; Email: \\ hubo@asch.whigg.ac.cn; $876901758 @$ @qq.com ; \\ *Author to whom correspondence should be addressed; E-Mail: hubo@asch.whigg.ac.cn; \\ Tel. /Fax: +86-20-3932-2530.
}

\begin{abstract}
Landslide is a sliding movement of rock mass, debris and soil along the slope under the action of gravity. Small Baseline Subset (SBAS) is an established method for the investigation and monitoring of landslide moments. This study focuses on monitoring the long-temporal displacement of mountainous terrain in Danba County, Sichuan Province via SBAS technique, based on 31 scenes of L-band ALOS/PALSAR data from Feb. 2007 to Oct. 2010.The results show that the largest velocity rates in LOS direction are $\pm 120 \mathrm{~mm} / \mathrm{yr}$ and maximum accumulated displacement is up to -300 , which indicates fast movement of the mountainous terrain during the observation time. These results get good consistency against the results of previous study. This demonstrates the strong potential of SBAS technique for monitoring the landslides geohazard.
\end{abstract}

Keywords: SBAS; landslide; Danba; time-series; displacement

\section{Introduction}

Landslide, refers to the slope failure in response to the increased ratio of destabilizing shear stress to resisting shear strength [1]. Nowadays, landslide has become a global geological issue that menaces the natural environment of human beings. Considered that landslide always appears on the brae and coteau area, and compared with the traditional leveling and global positioning system measurement methods, Interferometric synthetic aperture radar (InSAR) technique can obtain a millimeter-level precision with a wide range of subsidence [2].

InSAR is a new type of space-to-Earth observation technique, taking full advantages of the phase information of the radar wave to measure surface deformation with high spatial resolution and high accuracy developed on the basis of SAR. However, problems due to changes in scattering properties of the Earth's surface with time and look direction limit the feasibility of InSAR [3]. To overcome the shortcomings of InSAR and retrieve long time-series subsidence data, the deformation velocity of highly coherent target points was computed by using least squares (LS) estimation [4]. Meanwhile, time-series InSAR techniques are proposed, including 
Persistent Scatterer Interferometry (PS) [5,6], Small Baseline Subset(SBAS)[7,8], and Stanford Method for Persistent Scatterers (StaMPS) [9,10]. Among which SBAS technique combined multiple small baseline subsets by the singular value decomposition (SVD) method based on InSAR data pairs with small spatial and temporal baselines [11]. Therefore, it can effectively solve the low correlation caused by long spatial and temporal baselines among SAR data sets for the purpose of obtaining the deformation of high coherence targets during different periods. In recent years, InSAR technique was used widely to monitor landslide $[12,13,14,15]$, earthquake $[16,17,18]$, urban subsidence $[19,20]$ and volcanic activities [21] as well as other crustal movement [22], and anthropogenic subsidence [23].

Recently, some researchers have investigated Danba County, especially Jiaju landslide using different techniques. Chengdu Geological Survey used D-InSAR technology to monitor the Jiaju landslide in Sichuan and obtained only two landslides, which results coincided well with GPS monitoring results [24]; Ao Meng et al. adopted an improved nonlinear artificial corner reflectors InSAR (CR-InSAR) algorithm based on phase coherence, which not only avoid the phase unwrapping error effectively, but also had the strong capability to detect the large scale deformation gradient [25]. Dong Jie et al. applied coherent scatterer InSAR (CSI) method to retrieve the historical displacement of the Jiaju landslide and found that the northern part of the landslide moved faster than the south part, exhibiting a maximum LOS displacement rate of around $120 \mathrm{~mm} / \mathrm{yr}[26]$.

The aim of this paper is to (1) investigate the holistic displacement of Danba County and its surrounding area using SBAS method; (2) perform a time series analysis and make comparison with SBAS result and GPS measurement in identified landslide (Jiaju landslide); (3) detect two other region with large velocity rates of deformation and analyze the possibility that landslide occurred.

\section{Study Area and Dataset}

\subsection{Study Area}

Danba, a big town in Sichuan Province, is located in the western region of Xiaojin town and the north of Kangting town. The geographical coordinates of Danba are $30^{\circ} 24^{\prime}-31^{\circ} 23^{\prime} \mathrm{N}$ and $101^{\circ} 17^{\prime}-102^{\circ} 12^{\prime} \mathrm{E}$. Its length from north to south is $105.7 \mathrm{~km}$, and the south - north width is 86.9 $\mathrm{km}$. Therefore, the covering of this area is approximately $5649 \mathrm{~km}^{2}$. Danba town belongs to the Qinghai-Tibet plateau monsoon climate, and shows the vertical belt distribution. The temperature difference between the top of the mountain and river valley is $24^{\circ} \mathrm{C}$. The annual average temperature is $14.2^{\circ} \mathrm{C}$.

Danba's terrain is high in the west and low in the east. The lowest elevation is $1700 \mathrm{~m}$ while the highest is $5820 \mathrm{~m}$. The landform of Danba town is mountainous type in mountains areas, which is made up by a set of linear fold in the parallel arrangement. And there is several fracture activity in Danba town, among which are mainly NW-trending, and Yuke-Danba fracture is the greatest impact on Danba's topography. It makes Danba's terrain show high elevation in the south and west of town and low elevation in the north and east of it. The study area as illustrated in Fig. 1. 


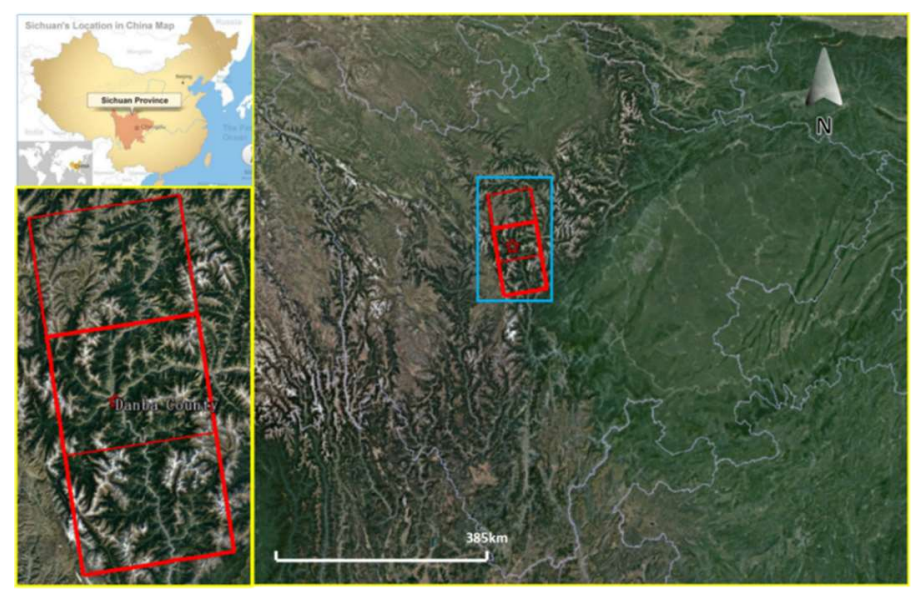

Figure 1. The location of the study area and the image coverage's of ALOS PALSAR data, the study area is outlined by two red rectangles.

\subsection{Dataset}

Two sets of ALOS-PALSAR data from 7 February 2007 to 3 October 2010 were used, along the north part (16 scenes, path number: 478 , frame number: 610 , see Table 1a) and the south part (15 scenes, path number: 478 , frame number: 600 , see Table 1b) were employed to analyze the landslide of the area around Danba town. Moreover, this study adopted L wave band as the working wave band, both single-polarization and cross-polarization modes. And the digital elevation model (DEM) data required for processing were 30m elevation of ALOS Global Digital Surface Model “ALOS World 3D - 30m” (AW3D30).

Table 1a. Imaging parameters and geometry of ALOS PALSAR-1 data used in the north part of Danba County

\begin{tabular}{c|c|c|c}
\hline $\begin{array}{c}\text { Path } \\
\text { Frame }\end{array}$ & $\begin{array}{c}478 \\
610\end{array}$ & $\begin{array}{c}\text { Direction } \\
\text { Angle of Incident(") }\end{array}$ & $\begin{array}{c}\text { Ascending } \\
34.5\end{array}$ \\
\hline \multirow{2}{*}{ No. } & $\begin{array}{c}\text { Acquisition Date } \\
\text { (yyyy/mm/dd) }\end{array}$ & No. & $\begin{array}{c}\text { Acquisition Date } \\
\text { (yyyy/mm/dd) }\end{array}$ \\
1 & $2007 / 2 / 7$ & 9 & 20090630 \\
2 & 20070810 & 10 & 20090815 \\
3 & 20070925 & 11 & 20090930 \\
4 & 20080210 & 12 & 20091231 \\
5 & 20080512 & 13 & 20100215 \\
6 & 20080627 & 14 & 20100703 \\
7 & 20081228 & 15 & 20100818 \\
8 & 20090212 & 16 & 20101003 \\
\hline
\end{tabular}

Table 1b. Imaging parameters and geometry of ALOS PALSAR-1 data used in the south part ofDanba County

\begin{tabular}{c|c|c|c}
\hline $\begin{array}{c}\text { Path } \\
\text { Frame }\end{array}$ & $\begin{array}{c}478 \\
600\end{array}$ & $\begin{array}{c}\text { Direction } \\
\text { Angle of Incident(") }\end{array}$ & $\begin{array}{c}\text { Ascending } \\
34.5\end{array}$ \\
\hline \multirow{2}{*}{ No. } & $\begin{array}{c}\text { Acquisition Date } \\
(\mathbf{y y y y} / \mathbf{m m} / \mathbf{d d})\end{array}$ & No. & $\begin{array}{c}\text { Acquisition Date } \\
(\mathbf{y y y y} / \mathbf{m m} / \mathbf{d d})\end{array}$ \\
1 & $2007 / 2 / 7$ & 9 & 20090630 \\
2 & 20070810 & 10 & 20090815
\end{tabular}




\begin{tabular}{l|l|l|l}
3 & 20070925 & 11 & 20090930 \\
4 & 20080210 & 12 & 20100215 \\
5 & 20080512 & 13 & 20100703 \\
6 & 20080627 & 14 & 20100818 \\
7 & 20081228 & 15 & 20101003 \\
8 & 20090212 & & \\
\hline
\end{tabular}

\section{Methodology}

Data processing starts with a stack of Single Look Complex (SLC) images. To minimize the effect of mis-corregistration caused by geometric, temporal, and Doppler decorrelation [27], all the SAR images are generated.

In our study area, due to the vegetation covering and subtropical monsoon climate, the application of SAR interferometry is mainly limited by temporal decorrelation. Besides, the land reclamation related deformation has limited spatial range. We processed the datasets with SBAS technology, and below (Figure $\mathrm{x}$ ) is a flow chart showing the strategy.

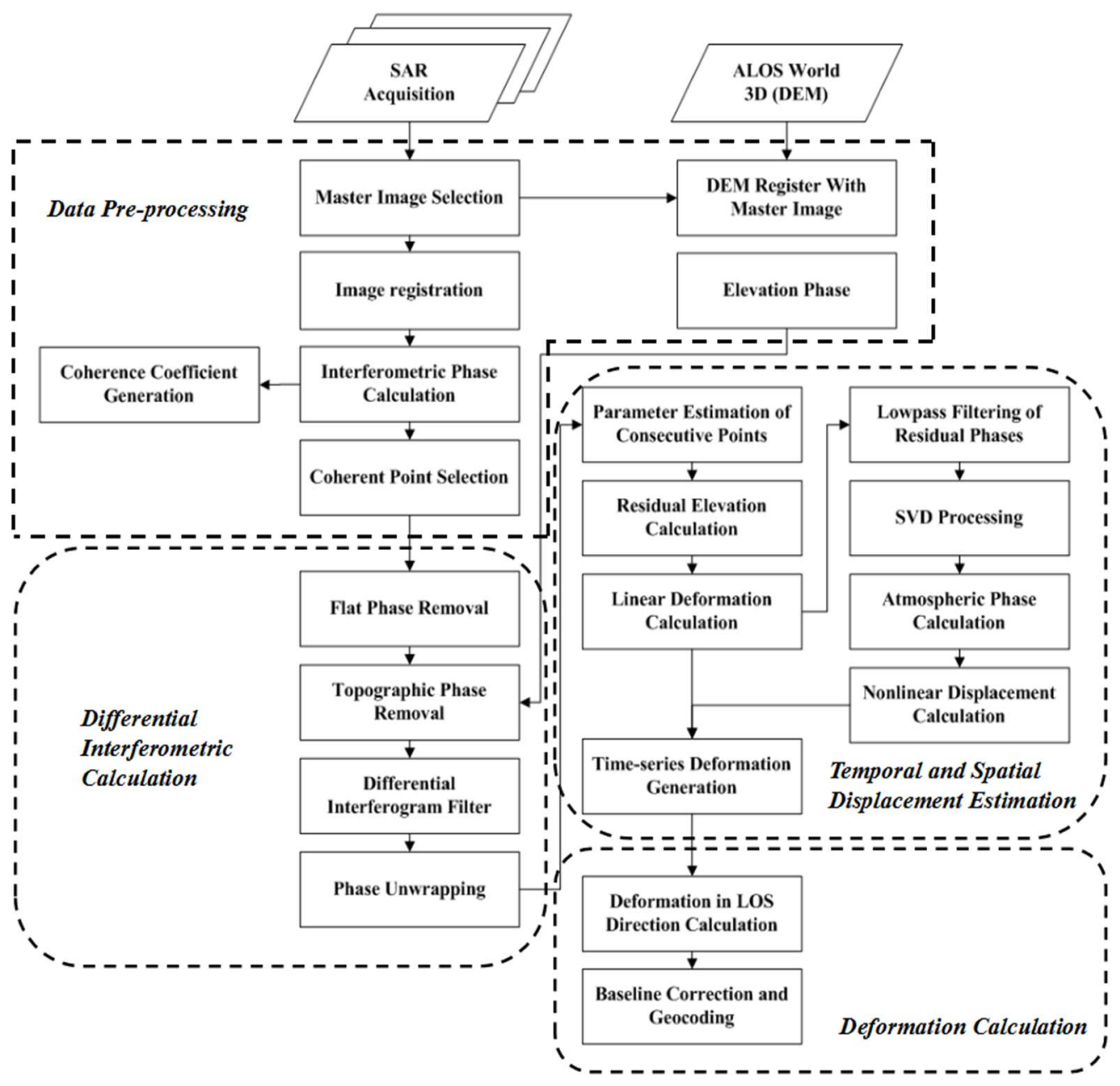

Figure 2. Flow chart of the SBAS

To minimize the effect of decorregistration caused by geometric, temporal, and Doppler, one of the advanced InSAR technology called small baseline subsets (SBAS) InSAR has been 
improved and applied since 2002 [7]. Interferograms with small baselines that overlap in time are used in the algorithm for the sake of relieving topographic and atmospheric errors, and, furthermore, reducing the spatial decorrelation in the time-serises interferometric pairs. The differential phase for a coherent generic pixel of the range and azimuth coordinates $(x, a)$ in $j$-interferogram that is generated by combining SAR acquisitions at times $t_{A}$ and $t_{B}$ is

$$
\begin{aligned}
& \delta \varphi_{\mathrm{i}}(x, r)=\varphi\left(t_{B}, x, r\right)-\varphi\left(t_{A}, x, r\right) \\
& \approx \frac{4 \pi}{\lambda}\left[d\left(t_{B}, x, r\right)-d\left(t_{A}, x, r\right)\right]+\frac{4 \pi}{\lambda} \frac{B_{\perp j} \Delta z}{R \sin \theta} \\
&+\left[\varphi_{\text {atm }}\left(t_{B}, x, r\right)-\varphi_{\text {atm }}\left(t_{A}, x, r\right)\right]+\Delta n_{j}, \forall j=1, \cdots, M
\end{aligned}
$$

where $\lambda$ is the transmitted signal central wavelength; $\varphi\left(t_{A}, x, r\right)$ and $\varphi\left(t_{B}, x, r\right)$ are the phases that correspond to times $t_{A}$ and $t_{B} ; d\left(t_{A}, x, r\right)$ and $d\left(t_{B}, x, r\right)$ are the LOS projection of cumulative deformation at times $t_{A}$ and $t_{B}$ as the reference to the instant $t_{0}$, when $\varphi\left(t_{0}, x, r\right)=0$. The formula also includes a phase term that is connected with error $\Delta \mathrm{z}$ in the knowledge of the scene topography to generate differential interferograms. The impact of these artifacts depends on the orbit separation component $B \perp_{j}$, sensor target distance $R$, and beam incident angle $\theta$. [ $\left.\varphi_{a t m}\left(t_{B}, x, r\right)-\varphi_{a t m}\left(t_{A}, x, r\right)\right]$ is used to account for possible atmospheric signal. Finally, the term $\Delta n_{j}$ includes decorrelation effects and other noise resources.

Therefore, Equation (1) can be expressed as follows:

$$
\delta \varphi_{j}(x, r)=\delta \varphi^{\text {disp }}{ }_{j}(x, r)+\delta \varphi^{a t m}{ }_{j}(x, r)+\delta \varphi^{n o i s e}{ }_{j}(x, r)+\delta \varphi^{\text {topo }}{ }_{j}(x, r)
$$

where $\delta \varphi^{d i s p}$, determined by Equation (3), is the slant displacement phase between times $t_{A}$ and $t_{B}$; $\delta \varphi^{\text {topo }}$ is the topographic phase error that is generated by external DEM; $\delta \varphi^{\text {atm }}$ is used to account for temporal atmospheric deformation obtained from different SAR acquisition; and $\delta \varphi^{\text {noise }}$ includes temporal decorrelation, orbital errors, thermal noise effects, etc [1].

The displacement between $t_{A}$ and $t_{B}$ can be expressed as follows:

$$
\delta \varphi^{\text {disp }}{ }_{j}(x, r)=\frac{4 \pi}{\lambda} \sum_{k=A}^{B-1} v_{k}\left(t_{k+1}-t_{k}\right)
$$

where $\mathrm{k}$ shows the sequence index of SAR acquisition time between $t_{A}$ and $t_{B}$, and $v_{k}$ indicates the mean phase velocity in the period from $k$ to $k+1$.

The cumulative displacement at different SAR acquisition times can be accounted by SVD methods when given $\mathrm{M}$ unwrapped interferograms.

\section{Results}

\subsection{Spatio-temporal Baseline Optimization}

All interferometric pairs within the thresholds of the spatial and temporal baselines were drawn to generate SAR data pair connection diagram (Figure $\mathrm{x}$ ) on account of a spatial baseline threshold, a temporal baseline threshold, and relative input parameters. In this study, the maximum normal baseline was set at $45 \%$, the maximum temporal baseline was set at 200 days. The system automatically screened the super master image (2009-09-30 in the South Area and 2009-02-12 in the north area). 


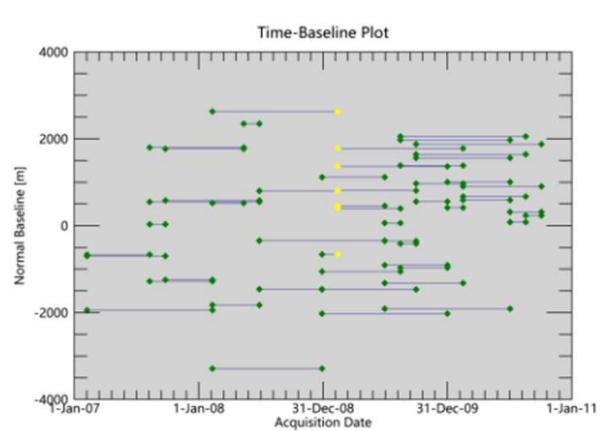

(a)

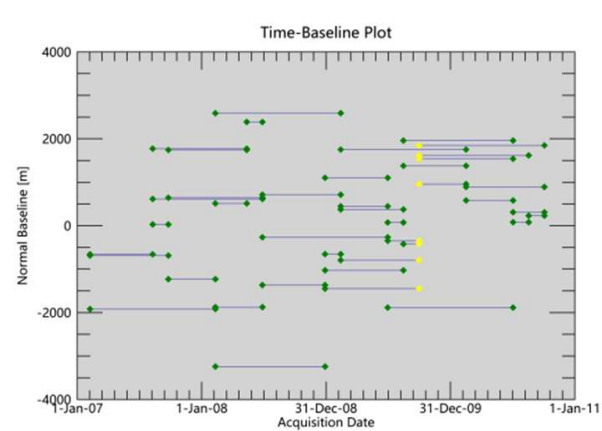

(b)

Figure 3. Time-baseline relevant to the ALOS PALSAR-1 images and interferograms used in this study. (a) refers to the north part of the study area while (b) refers to the south part of the study area.

\subsection{Interferometry Results}

According to the relationship of their connection based on the selected parameters of SBAS technique, interferometry was carried out on each pair, and 51 interferograms of north part and 40 interferograms of south part were chosen to be processed finally. Afterwards, the total time-series cumulative phase subsidence diagrams were detected by refining, reflattening, phase unwrapping and geocoding. The locations and the average surface displacement velocity detected by SBAS technique in the study area are shown in Figure 4. The maximum settlement center is Jiaju, in which the deformation velocity even exceeds $120 \mathrm{~mm} / \mathrm{yr}$, in the LOS direction. The mean subsidence velocity map illustrates a stable pattern (-24 to $24 \mathrm{~mm} / \mathrm{yr}$ ) in the large proportion of this study. Moreover, the time-series images of these two database are collected in Figure 5 totally.
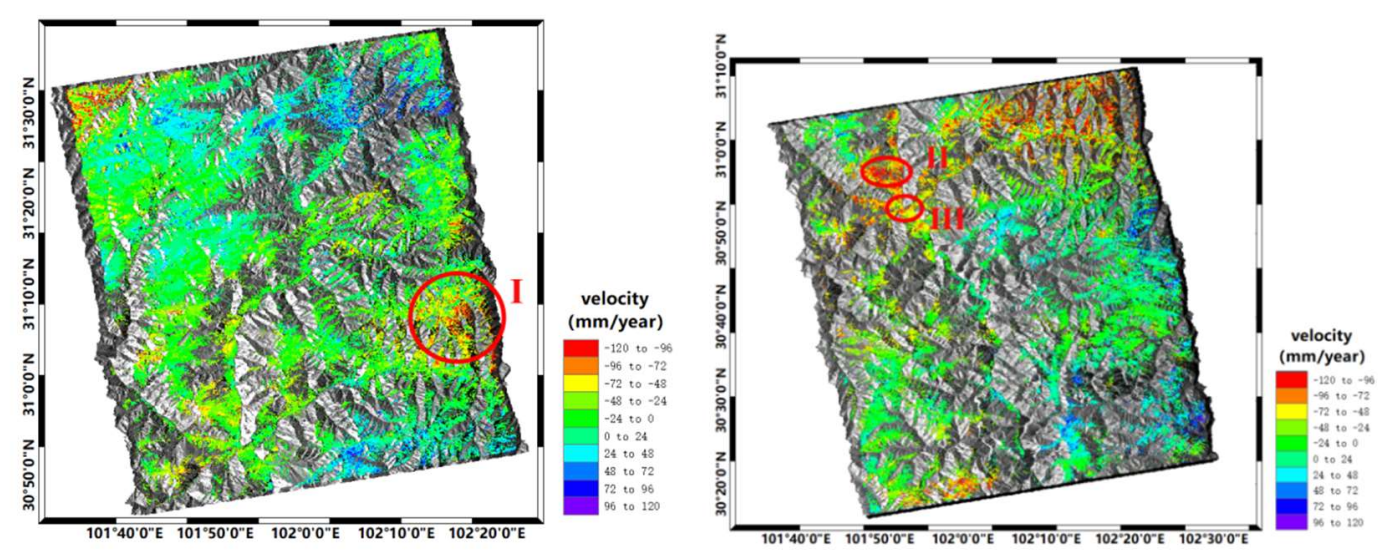

Figure 4. Mean displacement velocity mas over the study area derived by SBAS technique. The first Figure is reflected in the LOS velocity of the north of the study are, while the second Figure expresses the LOS velocity of the south part. The red ellipses indicate the area in which violent subsidence take place $(1,2,3) .1$ is the summit of mountain, 2 is Jiaju village and 3 refers to Danba town.. 

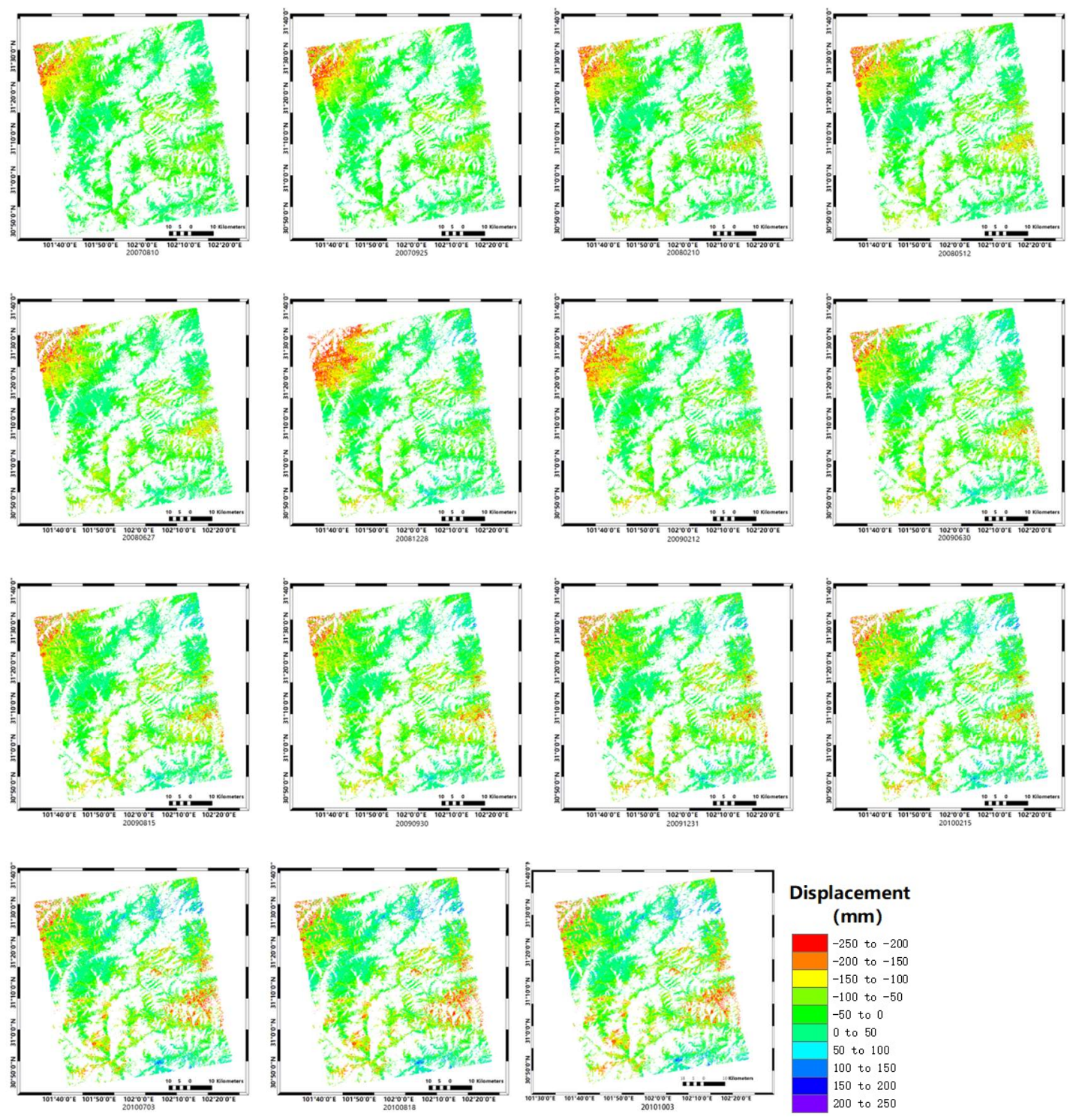

(a)
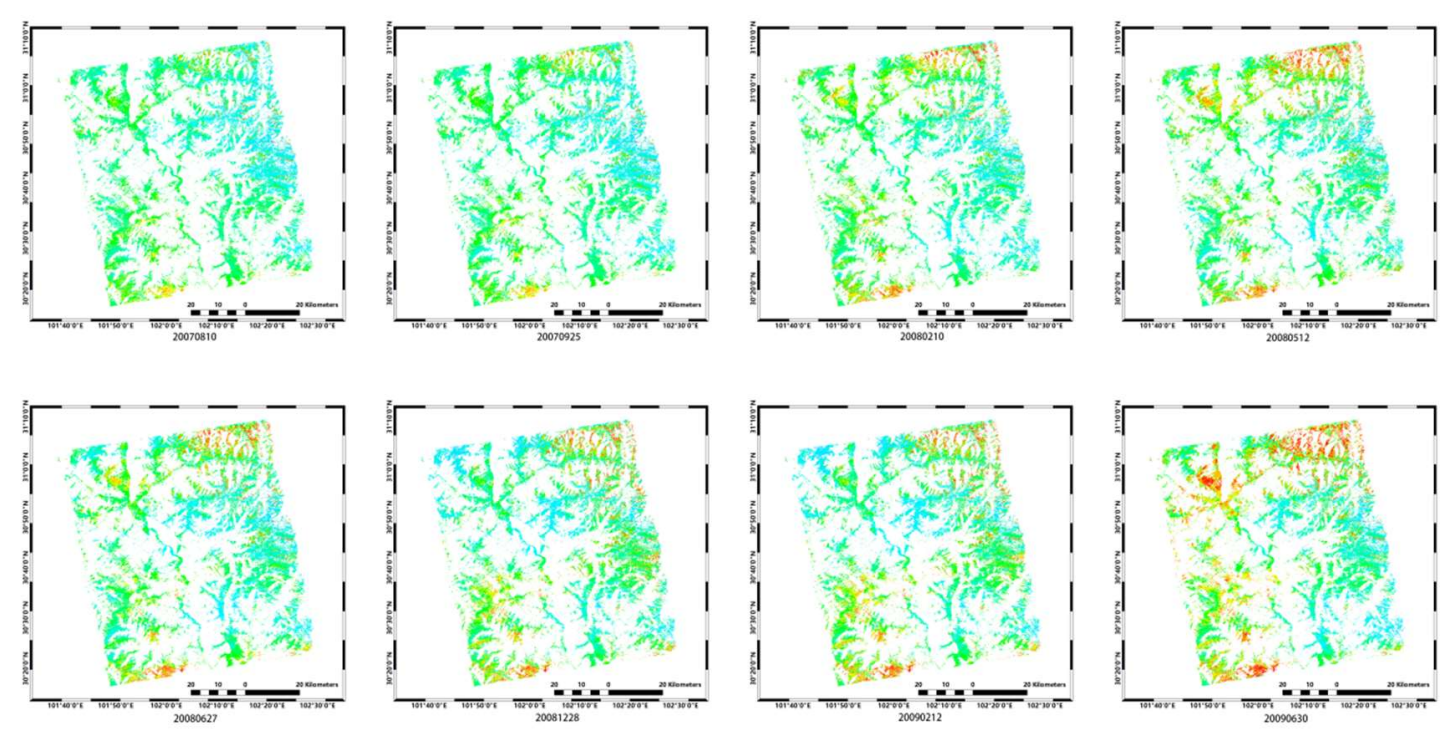

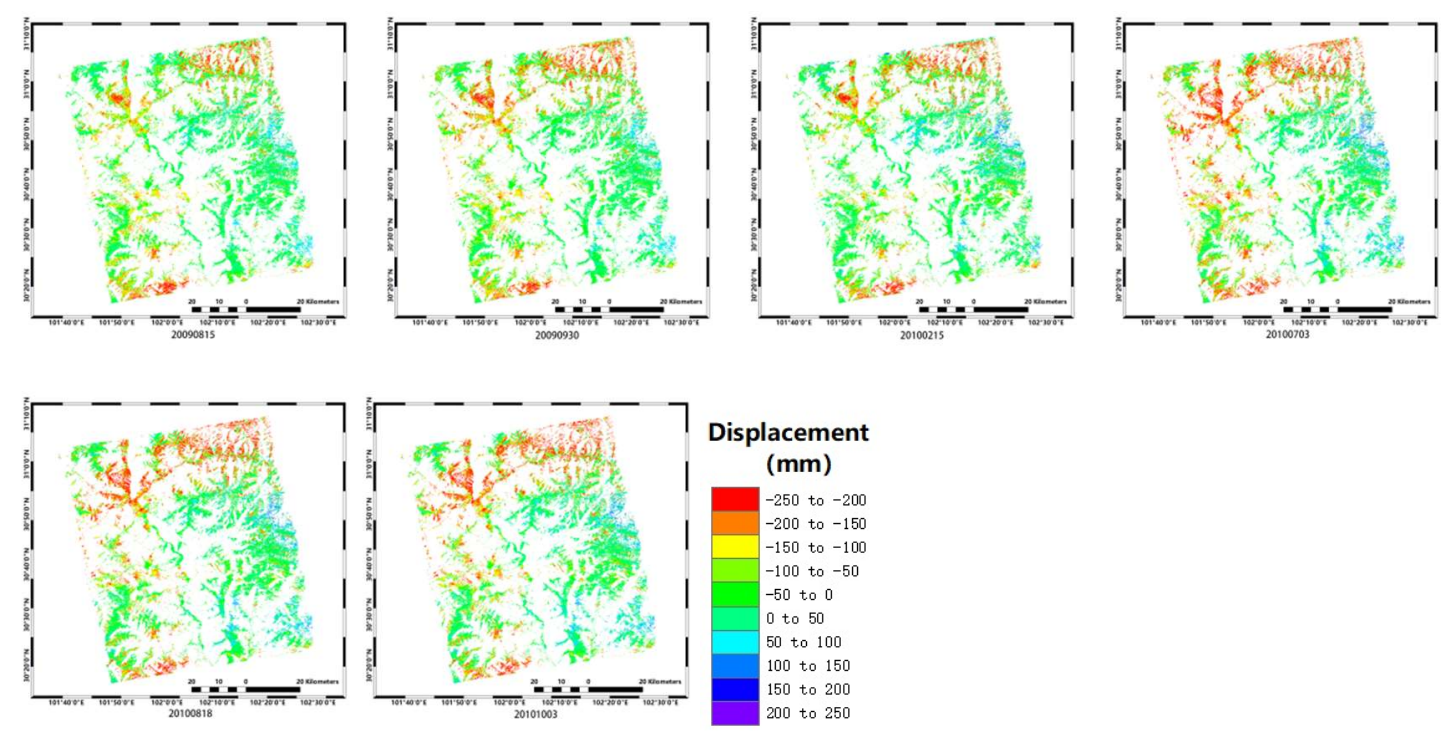

(b)

Figure 5. Time-series results of SBAS in study area. 5(a) describes the time-series displacement in north of Danba town, and 5(b) shows the long-term subsidence in south of Danba town.

\subsection{Validation by GPS measurements}

In order to estimate the accuracy and reliability of results processed by SBAS technique, we compare the time series displacements made by SBAS and GPS measurements. The time series displacement of these GPS monitoring stations are plotted in Figure.6. Generally, some parts of the results detected by SBAS technique match well with GPS measurements. As shown in Figure 6 , the differences of displacement between GPS and SBAS results results are around $20 \mathrm{~mm}$, and evolution trends are also similar.

The differences between InSAR and GPS results may rely on a few factors, among which match of spatial between these two technique and the discontinuous observation are two key factors to make SBAS and GPS results have discrepancies. Normally, contrasted with GPS observations, the long-term, large-scale, all-day InSAR technique can provide measurement points at higher resolution, and detect more points than traditional measurements.

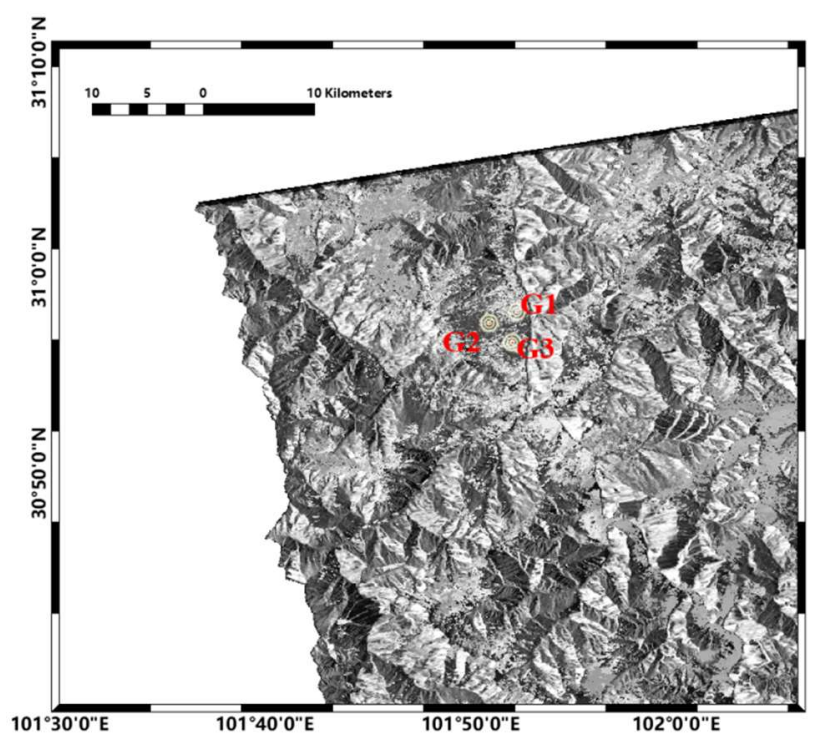

(a) 

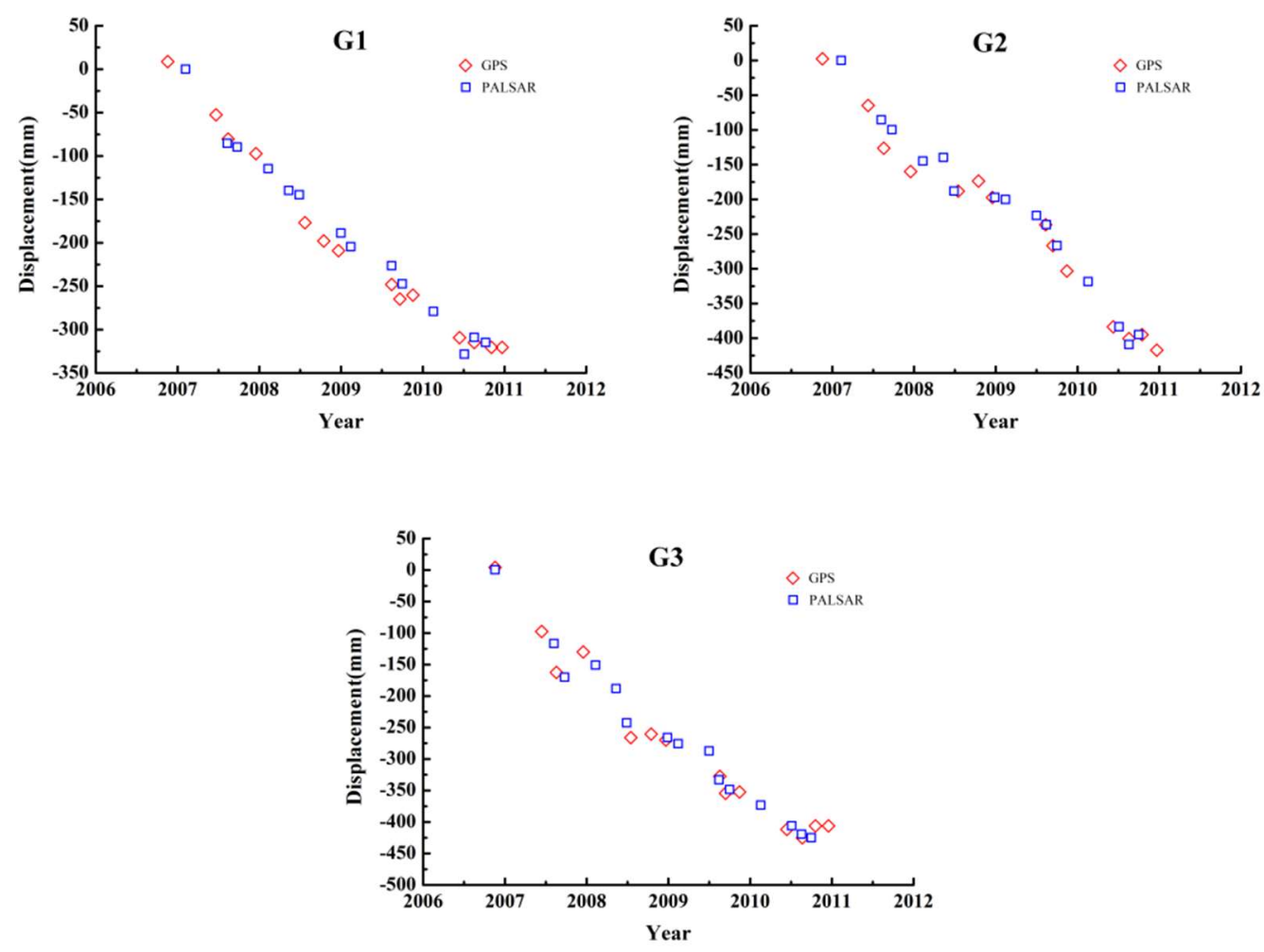

(b)

Figure 6. (a) shows the position of 3 GPS monitoring stations G1 G2 and G3, (b) indicates time series displacements at 3 GPS monitoring stations shown in (a). The red rhombus and blue square are GPS and PALSAR, respectively.

\section{Discussions}

It can be observed in Figure 3 that three large subsidences are detected in the study area, which are the summit of mountain. Jiaju village and Danba town. In order to intuitively analyze the subsidence of these three large displacements, some feature points (e.g., P1, P2, P3, P4, P5, $\mathrm{P} 6, \mathrm{P} 7, \mathrm{P} 8, \mathrm{P} 9, \mathrm{P} 10)$ in the study area are chosen to be analyzed the time-series displacements (Figure 7). Thereinto, P1 to P3 belong to Ellipse I, the displacement of P4, P5, P6 are shown in Ellipse II, and P7 to P10 are in the Ellipse III, so that each zone can be detected via the displacements of points on them respectively.

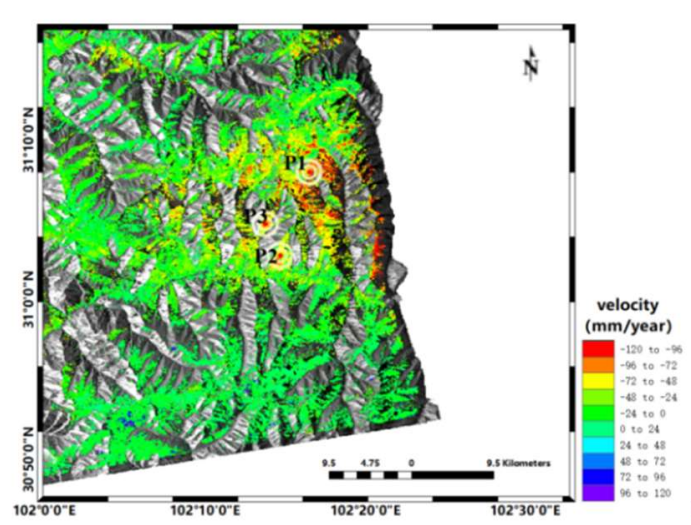

(a)

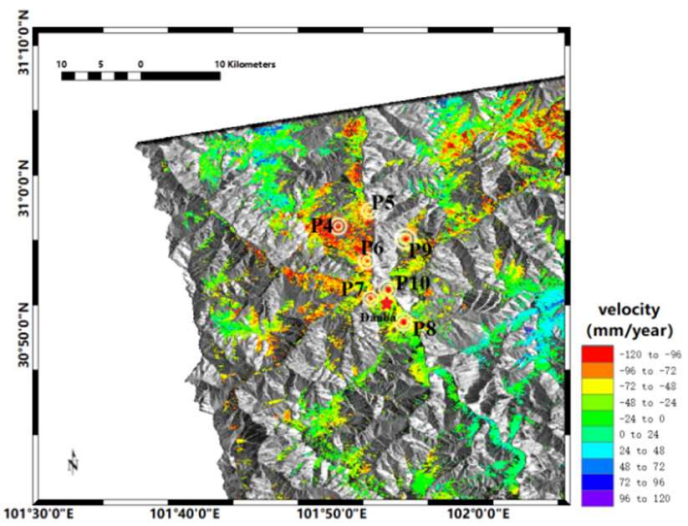

(b) 
Figure 7. The area contains Ellipse I, II and III. (a) include Ellipse I, and (b) comprises following two Ellipses.

\subsection{Mountains (Ellipse I)}

In Ellipse I, the summit of mountains is covered with snow for most of year, and, to a great extent, snow melting can affect the displacement of this area. Figure 8 reveals the time series deformation of P1, P2, and P3. It can be known from Figure 8 that the displacements of P1, P2, and $\mathrm{P} 3$ are changing periodically while the general tendency is descending. They are upraised from Aug. to Feb. every year, and reach the zenith of a year for every Feburary. The accumulated displacement from Feb. 7, 2007 to Oct. 3, 2010 is $-220 \mathrm{~mm},-240 \mathrm{~mm}$ and $-260 \mathrm{~mm}$ seperatelly. Considered the geographic feature, it is deduced that the periodic change is caused by snow covered on the summit of the mountain and that there is a danger of landslide on the summit of mountain.

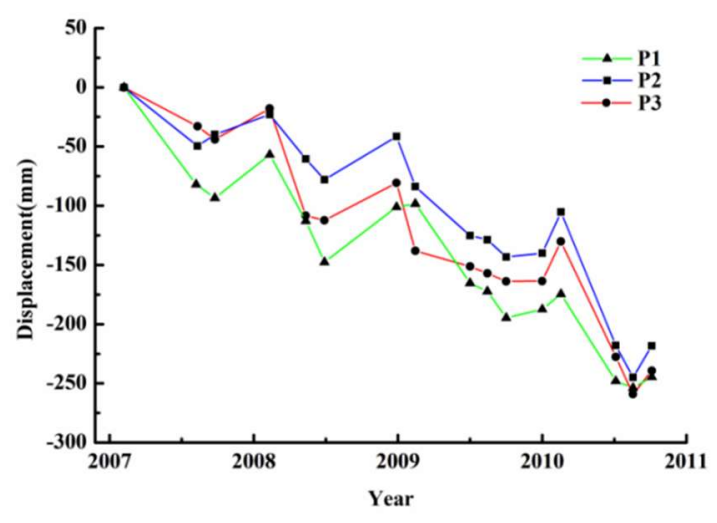

Figure 8. The figure status the time-series displacement of P1, P2 and P3 within Ellipse I. The green, red, and blue line describe the tendency of subsidence of P1, P2 and P3 separately.

\subsection{Jiaju village (Ellipse II)}

Jiaju village is rated as one of the most beautiful Chinese village.There is an area of landslide that was detected and called Jiaju landslide, which is $5.3 \mathrm{~km}$ far away from Danba town. The overall planar shape of Jiaju landslide is " $\mathrm{M}$ " ${ }^{24}$, and the shape of the section is nearly stepped, which consists of two secondary landslides. The east-west average length is about $1200 \mathrm{~m}$ and the mean width is about $1000 \mathrm{~m}$ from north to south. The soil belongs to a large tractor in the deep soil landslide and the average thickness is $22 \mathrm{~m}$. There is no uniform sliding surface and main slip direction in the Jiaju landslide area, which is mainly manifested as multi-stage deformation.

Three feature points P4, P5, P6 was chosen in this area. P4 is located in the top of Jiaju village, while P5 and P6 are situated near the roadside (Figure 9). From Figure 9, it can be known that between Feb. 2007 and May 2008, the trend of displacement was descending. Then, this area was suffered lifting for about 6 months since Wenchuan Earthquake happened. And finally, it return to descend. Due to the values of these time-series of subsidences are more than $-200 \mathrm{~mm}$ even up to $-300 \mathrm{~mm}$ in these years, it is speculated that there is a possibility that the landslides occurred. 


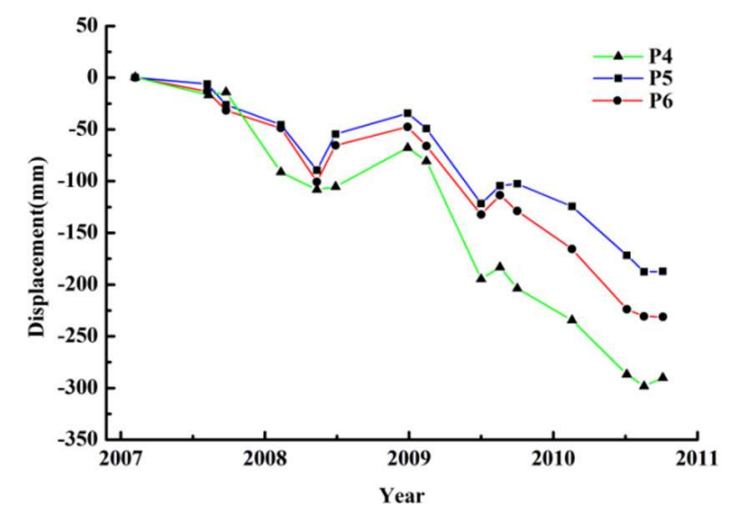

Figure 9. The figure is used to show the position and LOS time-series displacement of three typical points (P4, P5 and P6). Color green, red, and blue lines represent the displacement of P4 to P6.

\subsection{Danba town (Ellipse III)}

Danba town is a big county that numerous human lives, and it is surrounded by several mountains, in which landslide will cause larger destruction. So that the problem that prevents ruining of this area has become a serious problem.

In order to obtain the time-series displacement of this area circled by Ellipse III, there are four typical points located in this area. Among them. P7 is on the southern hillside of Danba County; P10 is on the northern back hillside of Danba; P8 and P9 are the point with obvious displacement and are both located near different highway. It can be seen from Figure 10 that there is the same tendency of these points as P7, P8, P9 and P10 in Ellipse III between Feb. 2007 and Jan. 2009. Then, they became to decline and upraised from Oct. 2009 to March 2010. The general displacement of these points are all less than $-300 \mathrm{~mm}$. On account of the trend and the velocity of displacement from Jan. 2009 to Oct. 2010 were larger them those in the period from Feb. 2007 to May 2008, and their variations since Jan. 2009 were unstable, it was deduced that there was a small landslide in Danba County and its surrounding at that time.

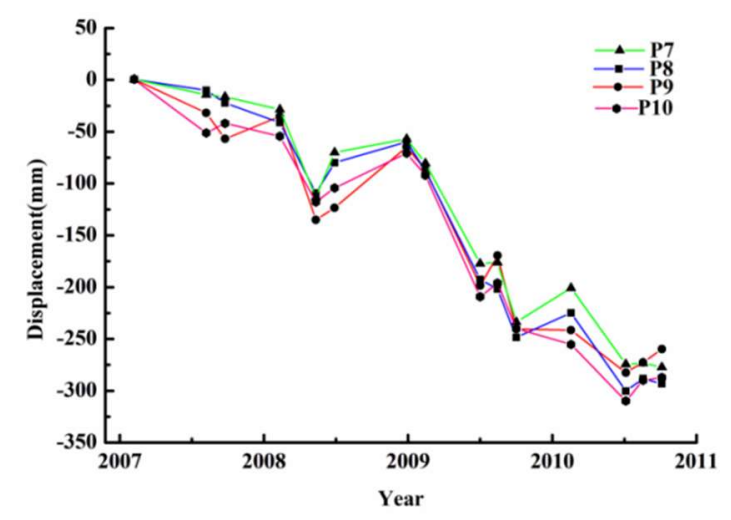

Figure 10. The figure shows the long-term variation of four typical points (P7, P8, P9 and P10) dipicted in Figure 6. The green, red, blue and pink lines respective refer to P7, P8, P9, P10.

\section{Conclusions}

In this study, SBAS technique allows us understand the annual velocity of subsidence under 
orographic factor in Danba town and its surrounding areafrom investigating utilizing totally 31 ALOS PALSAR-1 data in the period between Feb. 2007 and Oct. 2010. The result in our paper reveals that the Danba County, especially Danba town, Jiaju village and the mountain located in northeast of Danba has experienced significant ground subsidence during the ALOS data period, in which the maximum average velocity in LOS direction is up to 120 and maximum accumulation exceeds $300 \mathrm{~mm}$.

We find that some uplift are occurred around Danba town after May 2008 in LOS direction, which may be caused by orbit error, inadequate operation of selecting the reference points, It is more likely unique phenomenon the havoc of 8.0 richer magnitude earthquake in Wenchuan. And we also observe that there is a saltus point in May 12, 2008 among the time-series displacement, which may be also influenced by the Wenchuan earthquake. Although we have not yet to find a more precise explanation, it should be the focus of our future work, and we will try to understand and explain this phenomenon counting on the spot measurements or high resolution SAR data, e.g., those acquired by TerraSAR-X, Cosmo-SkyMed, Radarsat-2 and Sentinel-1.

\section{Acknowledgments}

This work was supported by the Science and Technology Plan Project in Fujian Province (grant No. 2017Y3004) and by the National Natural Science Fundation of China (Grant No. 41204012 and 41674006). We wish to thank the Japanese Aerospace Agency (JAXA) for arranging the ALOS PALSAR data and "ALOS World 3D - 30m" data. We also thank China Geological Survey for providing the GPS observation data. We thank the anonymous editor for their influential suggestions.

\section{Conflicts of Interest}

The authors declare no conflict of interest.

\section{References}

1. Ma, C.; Cheng, X.; Yang, Y.; Zhang, X.; Guo, Z.; Zou, Y., Investigation on Mining Subsidence Based on Multi-Temporal InSAR and Time-Series Analysis of the Small Baseline Subset - Case Study of Working Faces 22201-1/2 in Bu'ertai Mine, Shendong Coalfield, China. Remote Sensing 2016,8 (11), 951.

2. Galloway, D. L.; Burbey, T. J., Review: Regional land subsidence accompanying groundwater extraction. Hydrogeology Journal 2011,19 (8), 1459-1486.

3. Zhang, L.; Ding, X.; Lu, Z., Ground settlement monitoring based on temporarily coherent points between two SAR acquisitions. ISPRS Journal of Photogrammetry and Remote Sensing 2011,66 (1), 146-152.

4. Usai, S., A least squares database approach for SAR interferometric data. IEEE Transactions on Geoscience and Remote Sensing 2003,41 (4), 753-760.

5. Ferretti, A.; Prati, C.; Rocca, F., Permanent Scatterers in SAR Interferometry. IEEE Transactions on Geoscience and Remote Sensing 2001,39 (1), 8-20. 
6. Ferretti, A.; Savio, G.; Barzaghi, R.; Borghi, A.; Musazzi, S.; Novali, F.; Prati, C.; Rocca, F., Submillimeter Accuracy of InSAR Time Series: Experimental Validation. IEEE Transactions on Geoscience and Remote Sensing 2007,45 (5), 1142-1153.

7. Berardino, P.; Fornaro, G.; Lanari, R.; Sansosti, E., A new algorithm for surface deformation monitoring based on small baseline differential SAR interferograms. IEEE Transactions on Geoscience and Remote Sensing 2002,40 (11), 2375-2383.

8. Zhou, L.; Guo, J.; Hu, J.; Li, J.; Xu, Y.; Pan, Y.; Shi, M., Wuhan Surface Subsidence Analysis in 2015-2016 Based on Sentinel-1A Data by SBAS-InSAR. Remote Sensing 2017,9 (10), 982.

9. Hooper, A.; Segall, P.; Zebker, H., Persistent scatterer interferometric synthetic aperture radar for crustal deformation analysis, with application to Volcán Alcedo, Galápagos. Journal of Geophysical Research 2007,112 (B7).

10. Du, Y.; Feng, G.; Li, Z.; Peng, X.; Zhu, J.; Ren, Z., Effects of External Digital Elevation Model Inaccuracy on StaMPS-PS Processing: A Case Study in Shenzhen, China. Remote Sensing 2017,9 (11).

11. Lanari, R.; Mora, O.; Manunta, M.; Mallorqui, J. J.; Berardino, P.; Sansosti, E., A small-baseline approach for investigating deformations on full-resolution differential SAR interferograms. IEEE Transactions on Geoscience and Remote Sensing 2004,42 (7), 1377-1386.

12. Zhao, C.; Lu, Z.; Zhang, Q.; de la Fuente, J., Large-area landslide detection and monitoring with ALOS/PALSAR imagery data over Northern California and Southern Oregon, USA. Remote Sensing of Environment 2012,124, 348-359.

13. Teshebaeva, K.; Roessner, S.; Echtler, H.; Motagh, M.; Wetzel, H.-U.; Molodbekov, B., ALOS/PALSAR InSAR Time-Series Analysis for Detecting Very Slow-Moving Landslides in Southern Kyrgyzstan. Remote Sensing 2015,7 (7), 8973-8994.

14. Sun, Q.; Zhang, L.; Ding, X. L.; Hu, J.; Li, Z. W.; Zhu, J. J., Slope deformation prior to Zhouqu, China landslide from InSAR time series analysis. Remote Sensing of Environment 2015,156, $45-57$.

15. Liu, P.; Li, Z.; Hoey, T.; Kincal, C.; Zhang, J.; Zeng, Q.; Muller, J.-P., Using advanced InSAR time series techniques to monitor landslide movements in Badong of the Three Gorges region, China. International Journal of Applied Earth Observation and Geoinformation 2013,21, 253-264.

16. Tralli, D. M.; Blom, R. G.; Zlotnicki, V.; Donnellan, A.; Evans, D. L., Satellite remote sensing of earthquake, volcano, flood, landslide and coastal inundation hazards. ISPRS Journal of Photogrammetry and Remote Sensing 2005,59 (4), 185-198.

17. Xu, G.; Xu, C.; Wen, Y.; Jiang, G., Source Parameters of the 2016-2017 Central Italy Earthquake Sequence from the Sentinel-1, ALOS-2 and GPS Data. Remote Sensing 2017,9 (11), 1182.

18. Lee, W.-J.; Lu, Z.; Jung, H.-S.; Ji, L., Measurement of small co-seismic deformation field from multi-temporal SAR interferometry: application to the 19 September 2004 Huntoon Valley earthquake. Geomatics, Natural Hazards and Risk 2017,8 (2), 1241-1257.

19. Lanari, R.; Lundgren, P.; Manzo, M.; Casu, F., Satellite radar interferometry time series analysis of surface deformation for Los Angeles, California. Geophysical Research Letters 2004,31 (23). 
20. Zhou, L.; Zhang, D.; Wang, J.; Huang, Z.; Pan, D., Mapping Land Subsidence Related to Underground Coal Fires in the Wuda Coalfield (Northern China) Using a Small Stack of ALOS PALSAR Differential Interferograms. Remote Sensing 2013,5 (3), 1152-1176.

21. Wang, T.; DeGrandpre, K.; Lu, Z.; Freymueller, J. T., Complex surface deformation of Akutan volcano, Alaska revealed from InSAR time series. International Journal of Applied Earth Observation and Geoinformation 2018,64, 171-180.

22. Qu, F.; Zhang, Q.; Lu, Z.; Zhao, C.; Yang, C.; Zhang, J., Land subsidence and ground fissures in Xi'an, China 2005-2012 revealed by multi-band InSAR time-series analysis. Remote Sensing of Environment 2014,155, 366-376.

23. Hu, B.; Wang, H.-S.; Sun, Y.-L.; Hou, J.-G.; Liang, J., Long-Term Land Subsidence Monitoring of Beijing (China) Using the Small Baseline Subset (SBAS) Technique. Remote Sensing 2014,6 (5), 3648-3661.

24. Yin, Y.; Zheng, W.; Liu, Y.; Zhang, J.; Li, X., Integration of GPS with InSAR to monitoring of the Jiaju landslide in Sichuan, China. Landslides 2010,7 (3), 359-365.

25. Ao, M.; zhang, q.; Zhao, C.; Liu, G., An Improed CR-InSAR Technoogy Used for Deformation Monitoring in Jiaju Landslide, Sichuan. Geomatics and Information Science of Wuhan University 2017,42 (3), 377-383.

26. Dong, J.; Zhang, L.; Tang, M.; Liao, M.; Xu, Q.; Gong, J.; Ao, M., Mapping landslide surface displacements with time series SAR interferometry by combining persistent and distributed scatterers: A case study of Jiaju landslide in Danba, China. Remote Sensing of Environment 2018,205, 180-198.

27. Xu, B.; Feng, G.; Li, Z.; Wang, Q.; Wang, C.; Xie, R., Coastal Subsidence Monitoring Associated with Land Reclamation Using the Point Target Based SBAS-InSAR Method: A Case Study of Shenzhen, China. Remote Sensing 2016,8 (8), 652. 